\title{
LA MARCHA HACIA LAS CORTES DE ALCALÁ DE 1348 \\ (Anotaciones a la conflictividad social en la Castilla de Alfonso XI)
}

\author{
Emilio Mitre Fernández \\ Cristina Guillén Bermejo
}

El reinado de Alfonso XI de Castilla se presenta a primera vista como bien documentado a través de los testimonios narrativos que de él se conservan.

Sin embargo, hay una etapa en la que existen abundantes lagunas: la que transcurre desde la toma de Algeciras en 1344 hasta la muerte del monarca en el cerco de Gibraltar seis años más tarde. Los dos testimonios en prosa a los que puede recurrirse (la Crónica publicada en su momento por la «Biblioteca de Autores Españoles», y la Gran Crónica, que lo ha sido recientemente por Diego Catalán y el Poema de Alfonso Onceno) resultan de muy escasa utilidad para la reconstrucción de este sexenio'.

Por ello, a fin de completar lo que fue el período final de la vida del vencedor de El Salado, es necesario acudir a otro tipo de fuentes. De entre ellas, las actas/cuademos/ordenamientos de Cortes de Castilla y León constituyen un apoyo de primer orden ${ }^{2}$. Los publicados por la Real Academia de la Historia en su momento resultan de extraordinaria utilidad, aunque a todas luces insuficientes. Los referidos a la etapa final del gobiemo de Alfonso XI son: de Alcalá, de $1345^{3}$; de Burgos, de este mismo año ${ }^{4}$, desde

I Sobre la cronística del reinado de Alfonso XI son de uso imprescindible los trabajos de D. CATALÁN, entre ellos aL a histografia en verso y en prosa de Alfonso XI a la luz de nuevos textos. III: Prioridad de la Crónica respecto a la Gran Crónican, en Anuario de Estudios Medievales, 1956.

${ }^{2}$ Para ello, es de interés la memoria de licenciatura de C. Gutu.ÉN, precisamente bajo el título: Las *cortes $*$ castellanas en la mayoría de edad de Alfonso XI (Contes, ayuntamientos. consejos. 1325-1347), presentada en la Universidad Complutense el 25 de junio de 1984.

3 Cortes de los antiguos reinos de León y Castilla, publicadas por la Real Academia de la Historia, tomo I, Madrid 1861, p. 477-483.

${ }^{4}$ Ibíd. p. 483-492. 
donde se pasa a las Cortes de Alcalá de $1348^{5} ;$ y, por último, a las de León de $1349^{6}$.

¿Qué posibilidades hay de poder completar el cuadro?

\section{¿HACIA UNA MEJOR CUANTIFICACIÓN DE LAS REUNIONES DE CORTES?}

Para los diversos reinados de la Castilla bajomedieval se ha podido llegar, mediante el análisis de documentación inédita y de trabajos parciales que se han ido publicando, a un mejor conocimiento de las asambleas convocadas por los reyes a las que asistieron representantes de las fuerzas sociales oficialmente reconocidas?

El término «cortes» se ha popularizado, aunque sea por analogía. Existen otros, como el de ayuntamientos o consejos, que permiten hablar, quizás, de un diferente alcance cualitativo y cuantitativo de las reuniones. $\mathrm{La}$ ambigüedad de conclusiones a las que podemos llegar es tanto mayor si tenemos en cuenta la utilización del término «ordenamiento» para designar ciertas disposiciones que no forzosamente se han promulgado en una reunión de cortes o en una asamblea asimilada a cortes.

A lo largo de los años finales del reinado de Alfonso XI puede llegarse a un "escalonamienton cronológico de testimonios que permiten un mejor conocimiento de las realidades generales del momento. La vía más especialmente utilizada son los textos referidos a cortes y otros documentos afines.

Así tendríamos:

- Ciertos testimonios conservados que hacen pensar en la celebración, durante los meses de mayo o junio de 1345 , de un ayuntamiento en León ${ }^{8}$. Las peticiones de los procuradores y las soluciones arbitradas

5Ibid. p. 492 a 626.

6 Ibíd. p. 627 a 637.

7 Caso, por ejemplo, de lo realizado para el reinado de Enrique III de Castilla por E. MrrRE en aLos cuadernos de Cortes Castellano-leonesas (1390-1407): Perspectivas para su estudio en el ámbito de las relaciones socialess, en Actas de las I Jornadas de Metodologia Aplicada de las Ciencias Históricas II, Historia Medieval, Santiago de Compostela 1975. Uno de los aspectos ha sido profundizado posteriormente por E. MrTRE y C. GRANDA, en *La participación ciudadana en las Cortes de Madrid de 1391\%, comunicación presentada en el Coloquio sobre la ciudad hispanica durante los siglos XII al XV7, celebrado en La Rábida en septiembre de 1981 .

8 Archivo Histórico Municipal de León, 24 junio de 1345. Este documento es el núm. 88 del Catalógo de Nieto, según figura en J. A. Martín Fuerte y C. Álvarez Ál varez: Archivo Histórico Municipal de León. Catalógo de los documentos. León, 1982.

También Biblioteca Nacional. Manuscrito 13098, fol. 145 r-146v. Madrid 28 de dic. de 1345 . 
por el poder real presentan una enorme similitud con las que figuran en la asamblea de León de 1349, similitud sobre la que sería conveniente profundizar.

- A principios de 1346 sabemos que Alfonso XI se encamina a la frontera desde Madrid. En el mes de febrero se encontraba en Jaén, según consta en carta dirigida a los oficiales y hombres buenos de Toledo', en la que manifiesta su intención de ir hacia Algeciras. Desde Sevilla, el 12 de abril de 1346, el monarca da un ordenamiento dirigido a los alcaldes y al alguacil de Madrid en el que se habla de la necesidad de mantener un equilibrio entre caballos y mulas. En última instancia, se establece la prioridad de los primeros ${ }^{10}$. Igualmente desde Sevilla y casi en la misma fecha (11 de abril) se había promulgado también un ordenamiento sobre actuación de los fieles, en el que se les permitía librar una serie de pleitos e imponer ciertas penas de azotes o de prisión".

- En los comienzos de octubre de 1346, Alfonso XI da, desde Madrid, una carta de ordenamiento para poner fin a las asonadas y otro tipo de desórdenes que se producían en Toledo y su tierra ${ }^{12}$.

- Promulgado el 30 de diciembre de 1346 es el ordenamiento de Villa Real, de importancia singular, estudiado por Rafael Gibert ${ }^{13}$.

- En 1347, por último, se promulga el Ordenamiento de Segovia, bien conocido merced al estudio de Galo Sánchez ${ }^{14}$. Se recogen las leyes dadas en el de Villa Real y se añaden otras referidas al procedimiento en caso de deudas, adulterios, muerte segura, etc.

\section{CORTES, CONFLICTOS SOCIALES Y PAZ SOCIAL}

Existe una tendencia (de la que el caso de Alfonso XI es verdadero arquetipo) a contraponer los años de regencia de un monarca con los de su gobierno personal. Hay un pasaje del Poema de Alfonso Onceno que se toma habitualmente como punto de referencia a la hora de presentar la

9 Archivo Secreto del Ayuntamiento. Toledo, Caj. 5, leg. 7, núm. 7.

10 Documentos del Archivo General de la Villa de Madrid, interpretados y coleccionados por T. DOMINGo PALACio, T. 1, Madrid 1888, p. 279 a 283.

11 Biblioteca Nacional Mss. 1398, fol. 149-150.

12 Archivo Histórico Nacional. Mierofilm del Archivo Municipal de Toledo, Caj. 572, rollo 3843.

$13 \kappa \mathrm{El}$ Ordenamiento de Villa Real de 1346*, en Anuario de Historia del Derecho Español, 1955.

14 «Ordenamiento de Segovia de 1347, en Boletín de la Biblioteca Menéndez y Pelayo IV, 1922. 
calamitosa situación de la Corona de Castilla en el momento de acceder el rey a la mayoría de edad:

En este tiempo los sennores

Corrian a Castiella

Los mesquinos labradores

Pasavan grant mansiella

Los algos les tomavan

Por mal e por codiçia

Las tierras se hermavan

Por mengua de justiçia ${ }^{15}$.

Sin embargo, ni 1325 supuso un radical cambio de la situación ${ }^{16}$, ni los años siguientes hasta la muerte del monarca fueron precisamente idílicos. La nobleza castellana se mantuvo en situación insumisa con harta frecuencia. Resulta sintomático que en vísperas nada menos que de la batalla de $\mathrm{El}$ Salado, según recoge el cronista, el monarca no se fiara mucho de la actitud que fuera a tomar su pariente don Juan Manuel ${ }^{17}$.

Pero también las dificultades se producían en otros niveles de la sociedad castellana. Sabemos, por ejemplo, de enfrentamientos entre caballeros urbanos y pequeños burgueses en localidades como Burgos, León y Segovia, en el período que discurre entre 1330 y 1350 . Conflictos en los que se solicitó la intervención del rey como poder arbitral ${ }^{18}$.

El caso de Toledo antes mencionado resulta extremadamente ilustrativo de la situación de la ciudad en 1346. Las disposiciones dadas por el rey en forma de carta de ordenamiento merecen un toque de atención.

En efecto, Alfonso XI se hace eco, en esta ocasión, de las quejas sobre enfrentamientos entre caballeros del lugar secundados por personajes de su entorno, que se dedicaban a tomarse la justicia por su mano prendiendo a caballeros y escuderos de linajes rivales. Éstos, a su vez, respondian con operaciones similares contra sus oponentes sin que tuviesen en cuenta a los alcaldes y alguazil encargados de administrar justicia. Tales operaciones se

15 «Poema de Alfonso Oncenom, en Biblioteca de Autores Españoles, tomo 57. Madrid 1972, p. 479.

16 Esta opinión comuín se recogía, por ejemplo, en la introducción de J. RODRicuzZ-PurkeTol as a su antología Poesía de protesta en la Edad Media castellana. Madrid 1968, p. 27. Sin embargo, con posterioridad, se ha procurado eludir por este mismo autor y C. BLANCo AgUINAGA y I. M. ZAvALA en Historia social de la Literatura española (en lengua castellana) I. Madrid 1978, p. 83-85.

17 «Coronica del muy alto et muy católico rey Don Alfonso el Oncenom, en Biblioteca de Autores Españoles, t. 66, Madrid 1953, p. 326.

${ }_{18}^{18}$ T. F. RuIz, Sociedad y poder real en Castilla (Burgos en la Edad Media), Barcelona 1981, p. 45. 
traducían en «assonadas de parientes o amigos para pelear y en la villa e en el término».

En consecuencia, el monarca ordena que nadie proceda a título personal a resarcirse de los males sufridos, sino que «lo querelle al nuestro alcalde de la justiçia». En caso contrario, se dan instrucciones para que el alcalde mande encerrar «al que prend6 o mando prendar» hasta que el monarca procediera a fijar la pena. Cuando en el plazo de tres días no hubieran podido las autoridades detener a los infractores, éstos serían castigados con pena de destierro de la villa y su término, por el plazo de un año. En caso de ser localizado el culpable en el interior de Toledo, sería encarcelado por el tiempo que durase la pena de destierro.

Por último, se determina categóricamente que no se hagan asonadas en Toledo, castigándose la infracción con una pena de dos meses de prisión para «los cavalleros o escuderos que a ellas venieren, salvo los que venieren con aquellos con quien viven».

El texto de la carta de ordenamiento de Alfonso XI a Toledo es lo bastante interesante como para analizarlo a la luz de una problemática: la derivada de la conflictividad social que acuciaba a la Castilla de aquellos años.

Hace diez años, en una obra de gran impacto entre los estudiosos del Medievo ${ }^{19}$, Julio Valdeón dijo que: «aún es posible, moviéndonos en un terreno puramente fáctico, descubrir numerosos conflictos sociales de tipo local que no han sido recogidos por las crónicas de la época y de los que, en el mejor de los casos, sólo se conservan testimonios indirectos o leves referencias registradas en documentos ignorados».

La referencia a las asonadas toledanas en los últimos años del reinado de Alfonso XI se ajusta a este esquema. Puede ser — creemos - motivo de algunas reflexiones que la lleven a ser algo más que un mero añadido inventarial a los grandes o pequeños conflictos que la Corona castellana conoció en el Bajo Medievo.

En efecto, se ha discutido sobre la conveniencia o no de utilizar el término clase y, consiguientemente, el de lucha de clases a la hora de definir cada una de las categorías sociales del Medievo y de hablar de sus distintos enfrentamientos.

G. Fourquin, por ejemplo, en una conocida y sumamente controvertida obra, se ha inclinado por la utilización del término estratos sociales que, a su gusto, es más acorde con las realidades de la sociedad medieval ${ }^{20}$.

${ }^{19}$ Las conflictos sociales en el reino de Castilla en los siglos xIV y XV, Madrid 1975, p. 13.

${ }^{20}$ Les soulevements populaires au Moyen Áge, París 1972, p. 56 y s. 
De acuerdo con la postura contraria, habría que admitir la existencia de luchas sociales $y$, consiguientemente, reconocer de forma implícita los enfrentamientos de clases. Tales enfrentamientos, de acuerdo con unas sumarias ideas matrices responderían a: choques campesinos-señores en el medio rural y confrontación pueblo-caballeros en las revueltas urbanas ${ }^{21}$. Esquema que sería el aplicable a la Castilla de los siglos finales del Medievo.

Esta dialéctica social en el medio urbano ha sido reiterada por el profesor Valdeón en distintos trabajos publicados en los últimos años en torno al tema que nos ocupa. Asf, ha podido recalcar recientemente que la ciudad desempeña un importante papel en la lucha antiseñorial y que «los textos castellanos de los siglos XIV y XV contienen abundantes referencias acerca de enfrentamientos entre los caballeros y el común, cuando no sublevaciones de los populares contra los privilegiados de la villas ${ }^{22}$.

Las tomas de posición en un sentido apasionado o acrítico raramente contribuyen a arrojar nueva luz sobre los problemas a estudiar. Retomando las palabras del propio profesor Valdeón, pensamos que el descubrimiento de nuevos conflictos de carácter local puede suponer un enriquecimiento beneficioso para todos.

El caso toledano denunciado por la carta de ordenamiento de 1346 no se ajusta, verdaderamente, a los marcos de una pugna de caballeros con el común o de grupos fuertes económicamente con los simples desheredados. No por ello, sin embargo, este esquema queda desautorizado, aunque obliga a tener en cuenta, a la hora de analizar la conflictividad social en un momento determinado, otra serie de factores.

Así es como se ha recordado repetidas veces la posibilidad de una alianza de clases teóricamente antagónicas contra un oponente que, aunque de forma puramente coyuntural, puede convertirse en un enemigo común. De la misma forma que hay que recordar también $-\mathrm{y}$ es el caso que ahora nos concierne-ciertas pugnas en las que más que de enfrentamiento de clases cabría hablar de enfrentamiento de clanes, tomando este término en el sentido más lato ${ }^{23}$. La ciudad, se puede decir, reproducía los esquemas feudales y sus confrontaciones más clásicas ${ }^{24}$.

21 J. VALDEÓN, op, cit., p. 31.

22 J. VAL DEÓN: «L Los conflictos sociales en los siglos XIV y xV en la Península Ibéricas en Anales de la Universidad de Alicante, 1984, p. 139-140.

${ }^{23}$ E. Mrrke, Historia de la Edad Media. I. Occidente, Madrid, 1983, p. 335.

24 Aunque remitiéndose esencialmente al caso de las ciudades italianas, este tema ha sido estudiado por J. HeErs en El clan familiar en la Edad Media. Barcelona 1978, especialmente p. 49 a 58. 
En efecto, a la hora de detectar el malestar que vive la ciudad de Toledo en estos momentos, es necesario tener en cuenta lo que pudiera considerarse como solidaridades verticales. Ello supone un enfrentamiento de caballeros y escuderos, junto con sus clientelas de vasallos, frente a sus iguales; algo que llega a tener para el conjunto del territorio toledano un potencial de perturbación social no desdeñable en absoluto.

Así, para el caso que nos concierne, la pugna de clanes, parcialidades, bandos locales... supone, en la mayoría de edad de Alfonso XI, una buena piedra de toque para calibrar la capacídad de reacción de la autoridad real. Y lo supondrá también en reinados sucesivos...

De acuerdo con una tesis muy común, ¿actuaron en estos años el rey y las cortes conjuntamente como instrumento legislador que intentó devolver la paz social a la corona castellana?

Si tomamos el hilo de los acontecimientos desde 1345 (como hemos hecho con anterioridad), las disposiciones previas a las Cortes de 1348 encaminadas a un apaciguamiento de la situación se van repitiendo.

Así, el 4 de febrero del mismo 1345, y dentro de los esquemas de la más pura imagen del rey medieval como personaje obsesionado por la buena administración de justicia, Alfonso XI remitió una carta al consejo de Sevilla. En ella se recordaba que se había ordenado «que los nuestros Alcaldes de la nuestra Corte e todos los otros Alcaldes de las cibdades e villas e logares de los nuestros regnos non tomen dineros nin oro nin plata nin donacion de qual manera e condicion que sean.... ${ }^{25}$.

Se trata de un intento de sanear la administración de justicia, que es enmarcable dentro de un amplio plan de reforzamiento de la autoridad real que desembocará en la magna convocatoria de Alcalá de Henares de 1348. Un plan en el que, por ejemplo, habría que situar también el establecimiento del Regimiento en algunos municipios ${ }^{26}$ o el envío de corregidores a algunas localidades ${ }^{27}$.

¿Son las Cortes el escenario de la promulgación de algunas de estas importantes medidas?

No forzosamente. El propio Gibert piensa que inciuso un ordenamiento de la categoría del de Villa Real no fue elaborado en una reunión de Cortes. Otras disposiciones análogas tampoco lo fueron en Cortes o asambleas similares.

La carta de ordenamiento dirigida a los toledanos en 1346 puede, a mayor abundamiento, llevarnos a pensar en una relación directa del rey con

${ }^{25}$ Biblioteca Nacional. Mss, 13098. fol. 131-134.

26 T. F. RUIZ, op. cit., p. 189.

27 Cf. A. Bermúnez AzNar: El corregidor en Castilla durante la Baja Edad Media (1348-1474), Murcia 1974. 
la ciudad, similar a la mantenida con Sevilla o Murcia, al margen del aparato de las Cortes ${ }^{28}$.

De todo ello puede inferirse que la labor de pacificación social $\longrightarrow 0$ al menos los serios intentos-emprendida por Alfonso XI desde el momento de tomar personalmente las riendas del gobierno, tuvo en muchas ocasiones un sentido puramente «sectorial»; tanto en lo que concierne a las distintas categorías sociales como a las diversas localidades y regiones de la Corona castellana. En esta tarea, además, se demostró que la pugna con el Islam y su mística, tan magníficamente reflejadas en el Poema de Alfonso Onceno, no constituían una válvula de escape lo suficientemente eficaz para la agresividad de algunos grupos de la sociedad castellana. Y una tarea, en definitiva, cuyas fallas se ponf́an demasiado en evidencia pese a los logros institucionalizadores de la Corona castellana ${ }^{29}$.

\section{A TÍTULO DE CONCLUSIÓN}

Lo que algunos autores han dicho para estados como el francés o el inglés en los albores del Bajo Medievo puede decirse también, en líneas generales, para el estado castellano-leonés.

Las estructuras de gobierno se habían desarrollado considerablemente a lo largo de los siglos XII, XIII e inicios del XIV, pero las debilidades internas eran demasiado patentes aún ${ }^{30}$. Los últimos años del reinado de Alfonso X y las minorías de Fernando IV y Alfonso XI fueron duras pruebas para el conjunto de la Corona. El vencedor de El Salado logró algunos éxitos que, dadas situaciones como las analizadas anteriormente, fueron forzosamente limitados. Su temprana muerte en el cerco de Gibraltar y la crisis general

28 El documento analizado y otros en los que Toledo presenta algunas peticiones al rey, permitieron a éste promulgar algunas disposiciones que se recogieron en ordenamientos posteriores. Todo ello serviría como prueba para la afirmación de A. García Gallo en su Manual de Historia del Derecho Español, t. I, p. 829, Madrid 1979, según la cual 1348 es el momento ken que por primera vez interviene Toledo en las Cortes dando así origen al enfrentamiento con Burgos sobre quien debía hablar en nombre de los procuradoress.

${ }^{20}$ Tema éste tratado en uno de sus últimos trabajos por S. de Moxó: «La sociedad política castellana en la época de Alfonso XIs, en Cuadernos de Historia. Anexos de la Revista Hispania, 1975. Y más puntualmente en un artículo también de este mismo autor, «La promoción política y social de los "letrados" en la Corle de Alfonso XIs en Hispania, 1975. Enormemente sugestiva, a este respecto, era la comparación que establecí́ el profesor Moxó entre ciertas actitudes políticas de Alfonso XI y las mantenidas unos años antes en Francia por Felipe IV en lo que se referia a la promoción de sgentes nuevas» para cargos de responsabilidad.

30 J. R. STRAYER: Sobre las origenes medievales del Estado moderno. Barcelona 1981. p. 94 
que se desató en los años siguientes ralentizaron aún más las innovaciones políticas.

Abundando en ello, se ha afirmado para el conjunto de Europa que el período entre 1345 y 1360 fue clave para el «el cambio de atmósfera» que frenó el proceso de burocratización impulsado desde años atrás por los príncipes $^{31}$. El enconamiento de la Guerra de los Cien Años es a la vez la causa y síntoma de este proceso.

Para Castilla, conflictos sociales como los mencionados para los últimos años del reinado de Alfonso XI y los más graves del período inmediato guardan, así, una estrecha relación con la limitada capacidad de la autoridad real y su aparato institucional para actuar como eficaces instrumentos de pacificación $^{32}$.

31 Puntos de vista sostenidos por B. GUENEE: "Y a-t-il un État des XIV et XV siècles? * en Annales (Éconamies, Sociétés, Civilisations), 1971; y del mismo autor, Occidente durante los siglos XIV y XV. Los Estados, Barcelona 1973, p. 216-217.

32 Idea esta que, sin embargo, convendría matizar, ya que el reforzamiento de la autoridad central puede convertirse en distintas ocasiones en factor de perturbación. E. MrTkE, Historia de la Edod Media, p. 337. Diversas situaciones derivadas de la implantación del sistema de corregidores son, en este sentido, demasiado elocuentes. 


\section{ANEXO}

1346 , octubre, 6, Madrid.

Carta de ordenamiento de Alfonso XI, por la que dispone no se prendan los unos a los otros en Toledo ni en su tierra, y que no hagan asonadas.

AHN Microfilm del Archivo Municipal de Toledo, caja 572, rollo 3843.

Sepan quantos esta carta de ordenamiento vieren, commo nos, don Alfonso, por la graçia de Dios, Rey de Castiella, de Toledo, de León, de Gallizia, de Sevilla, de Córdova, de Murçia, de Jahen, del Algarbe, de Algezira e sennor de Molyna, a los alcaldes e alguazil de Toledo que agora son o seran de aqui adelante a qualquier o qualesquier de vos a quien esta nuestra carta fuere mostrada. Salud e graçia. Sepades que nos fezieron entender que y en Foledo $\mathrm{e}$ en su término que recresçen muchas contiendas e bolliçios, senaladamiente porque quando algund cavallero o escudero o otros por su mandado prenden a otros cavalleros o escuderos o a sus vasallos por algún danno que dizen que de ellos resçiben, que aquel o aquellos que assy son prendados en los sus bienes o de sus vassallos, non lo quieren querellar al nuestro alcallde de la justiçia, mas prendan ellos o mandan prendar a aquellos que los prendaron o mandaron prendar o a sus vassallos por su abtoridat. E otrossy, que fazen assonadas de parientes o amigos para pelear y en la villa e en el término. Et nos, veyendo que esto que es grand nuestro deserviçio e podria por ello venir a los que moran en Toledo e en su término grande danno e grande despoblamiento, tenemos por bien de lo ordenar en esta guisa: que, sy algund cavallero o escudero de Toledo prendare bienes de otros cavalleros o escuderos o de sus vasallos, que aquel que fuere prendado, si entendiere que fue prendado a tuerto, que non pueda él por sy nin por otrie prendar mas que lo querelle al nuestro alcalde de la justiçia. E sy él prendare por sy o por otrie sin mandado del alcallde, que el alcallde que ge lo faga tornar con el quatro al tanto al querelloso e demás, que el alcallde que faga prendar al que prendó o mandó prendar e lo tenga presso e lo non de suelto ni fiado fasta que to nos sepamos e mandemos sobre ello lo que la nuestra merçed fuere; e sy por aventura fecha la prenda en ante que lo el alcallde faga prender, se alçare de la villa que el alcallde que lo faga pregonar. E sy fasta terçer dia non se veniere meter en la nuestra prission de y de Toledo, que sea desterrado de la villa e del término por un anno. E sy en este tiempo entrare en la villa o en el término, que sea doblado el tiempo del desterramiento. E sy, por aventura, en este dicho tiempo pudiere ser tomado en la villa o en el término, que yaga en la cadena tanto tiempo quanto avia de andar fuera de la villa e del término. Otrosy, que ningund cavallero nin escudero non fagan assonadas en Toledo nin en su término por alguna razón. Et contra los que las fezieren que passe el alcallde segund que en este nuestro ordenamiento sobre dicho se contiene; e los cavalleros o escuderos que a ellas venieren, salvo los que venieren con aquellos con quien viven, que sean desterrados de Toledo e de su término por dos meses. Porque vos mandamos que esto, que lo fagades luego assy apregonar por y por Toledo e por las plaças dende, e que lo guardedes e fagades guardar bien e 
complidamente según que en este dicho nuestro ordenamiento se contiene. Enon fagades ende al, so pena de la nuestra merçed e de los cuerpos e quanto avedes. E desto mandamos dar esta carta de ordenamiento sellada cn nuestro sello de çera colgado.

Dada en Madrit, seys dias de octubre, era de mill e trezientos e ochenta e quatro annos.

Yo Johan Ferrandez, la fiz escrivir por mandado del Rey. Ruy Diaz. 